\title{
Extracción y caracterización de antígeno micelial de Aspergillus fumigatus
}

\author{
Bernarda Cuadrado ${ }^{1}$, Doris Gómez ${ }^{2}$
}

\begin{abstract}
Resumen
Este estudio presenta la estandarización y caracterización antigénica de un extracto micelial de Aspergillus fumigatus, con el fin de utilizarlo posteriormente en pruebas diagnósticas de aspergilosis pulmonar.

Para la evaluación del antígeno micelial, se emplearon técnicas de doble inmunodifusión (DD), contrainmunoelectroforesis (CIE+ ID) y enzimoinmunoensayo (ELISA), comparando sus resultados con un antígeno de referencia. La concentración de proteínas y carbohidratos del antígeno estudiado fue de $8.800 \mu \mathrm{g} / \mathrm{mL}$ y $2.452 \mu \mathrm{g} / \mathrm{mL}$ respectivamente, muy similares a los encontrados en el antígeno de referencia. Los antígenos analizados presentaron bandas de identidad total y parcial en la DD. No hubo bandas de precipitinas al enfrentar ambos antígenos con 20 sueros negativos, utilizando las pruebas de DD y $\mathrm{CIE}+\mathrm{ID}$. En la $\mathrm{CIE}+\mathrm{ID}$ se presentaron precipitinas en los lados anódico y catódico de ambos antígenos. El punto de corte determinado en la prueba de ELISA para el antígeno del estudio fué de 0,352 , con un intervalo de confianza del $95 \%$. Es posible concluir que el antígeno micelial estudiado puede ser empleado en pruebas serológicas diagnósticas.
\end{abstract}

\section{Summary}

This report describes the standardization and antigen characterisation of a mycelial extract of Aspergillus fumigatus, for the purpose of employing it later in pulmonary aspergillosis diagnostic tests.

The mycelial antigen was evaluated using double-immunodiffusion (DD), counterimmunoelectrophoresis (CIE+ID) and enzyme immunoassay (ELISA) techniques, the results were compared with a reference antigen. The protein and carbohydrate concentrations of the mycelial antigen were $8,800 \mu \mathrm{g} / \mathrm{mL}$ and $2,452 \mu \mathrm{g} / \mathrm{mL}$, respectively, being very similar to the reference antigen. The antigens analysed in the DD presented bands of partial and total identity. No precipitin bands were presented in DD and CIE+ID tests when both antigens with 20 negative sera were run. In the CIE+ID, precipitin bands were observed at the anodic and cathodic poles for both antigens. The cut-off value determined in the mycelial antigen ELISA test was 0.352 with a $95 \%$ confidence interval. It is possible to conclude that mycelial antigen can be used in diagnostic serological tests.

Médico y Cirujano, M.Sc. en Microbiología; Docente, Departamento de Bromatología y Nutrición, Facultad de Ciencias Químicas y Farmacéuticas, Universidad de Cartagena, Cartagena.

2 Bacterióloga, M.Sc. en Microbiología; Docente de postgrado en Microbiología, Universidad de Cartagena, Cartagena. 
Las micosis producidas por hongos oportunistas son padecimientos generalmente graves $y$, a veces, mortales (1). Dentro de este grupo de microorganismos oportunistas se encuentra Aspergillus fumigatus, que produce el $90 \%$ de las infecciones atribuidas al género Aspergillus (24).

En la actualidad, debido a que la incidencia de infecciones causadas por estos hongos oportunistas y, en especial por el $A$. fumigatus, considerado con frecuencia como contaminante, ha ido en aumento (5-8); los laboratorios clínicos generalmente siguen un protocolo estándar, con el fin de demostrar la presencia de elementos fúngicos en los tejidos o líquidos corporales, mediante el uso de cultivos repetidos o por estudios histopatológicos (9-11). Sin embargo, no siempre se obtienen buenos resultados, ya que la técnica de cultivo, además de demorada es inespecífica y un solo aislamiento no es suficiente para establecer que el hongo aislado es el verdadero agente etiológico de la enfermedad. Lo anterior crea la necesidad de desarrollar pruebas diagnósticas ya sea de tipo serológico o mediante la utilización de técnicas de biología molecular (12-15). Dichas pruebas para que sean útiles al clínico, deben ser de alta sensibilidad y especificidad para que le permitan ordenar un tratamiento adecuado y eficaz (4).

La mayoría de los diagnósticos y estudios inmunológicos de aspergilosis por $\boldsymbol{A}$. fumigatus, se centran principalmente en el uso de antígenos que son parte integral del micelio del hongo o de los productos extracelulares que demuestran propiedades de unión a IgG e IgE (16-19) y aunque se han observado variabilidades aún entre lote y lote de un antígeno proveniente de una misma colonia (20-23), esta variabilidad es menor en los antígenos que provienen del micelio roto que en los tradicionalmente preparados a partir de filtrado de cultivo, lo que se refleja en los resultados de las pruebas donde se utilizan dichos antígenos (24-27).

El propósito del presente estudio fue estandarizar y caracterizar un extracto micelial de $A$. fumigatus, evaluando sus características bioquímicas y antigénicas, enfrentándolo con un antígeno y un suero positivo de referencia, con el fin de que una vez demuestre ser un reactivo óptimo para uso diagnóstico, pueda ser empleado posteriormente para realizar pruebas serológicas de gran sensibilidad y especificidad como son la doble difusión en gel de agarosa, contrainmunoelectroforesis y enzimoinmunoensayo (ELISA).

La técnica de extracción del antígeno micelial, una vez estandarizada, podrá ser aplicada para obtener antígenos de otras especies de hongos del género Aspergillus de reconocida patogenicidad como son: $A$. niger, $A$. flavus, $A$. terreus y $A$. nidulans (28-30).

El poder utilizar un antígeno nativo en pruebas diagnósticas de tipo serológico contribuirá a mejorar el manejo de nuestros pacientes con sospecha de aspergilosis pulmonar causada por A. fumigatus; confirmará la presencia del hongo haciendo un diagnóstico correcto; $y$, facilitará la aplicación de un tratamiento adecuado con disminución de costos tanto para el enfermo como para la institución, con el consiguiente ahorro de tiempo para el médico ya que inicialmente sólo se contaba con las tinciones y cultivos de los especímenes clínicos y se carecía tanto de antígenos propios como de pruebas serológicas aplicables al estudio de las aspergilosis en la región.

Todo lo anterior ocasionaba, a su vez, que muchos pacientes con una sintomatología sospechosa y en cuyas muestras clínicas no era posible aislarlo, como en el caso del aspergiloma o de aspergilosis broncopulmonar alérgica, se quedaban sin diagnóstico y, por consiguiente, con tratamientos inadecuados.

\section{Materiales y métodos}

Muestras: para obtener el antígeno micelial de A. fumigatus, se utilizó una cepa aislada a partir de muestras repetidas de esputo de un paciente con diagnóstico clínico y paraclínico de aspergilosis pulmonar. Esta cepa fue evaluada macro y microscópicamente, sembrándola en agar Czapek y agar Sabouraud, incubándose a 25 y $37^{\circ} \mathrm{C}$ e identificándola finalmente, teniendo en cuenta los criterios de Raper (31).

Obtención del antígeno: para la obtención del antígeno se adaptó la técnica descrita por 
Haynes, et al. (32), con algunas modificaciones. Una vez identificada la cepa de $A$. fumigatus, fue cultivada en agar Sabouraud por espacio de siete días para, posteriormente, hacer una suspensión de $10^{6}$ conidias e incubarla en medio Sabouraud líquido en atmósfera de aerobiosis y sometiéndola a agitación constante.

Este cultivo inicial se transfirió a $2.500 \mathrm{~mL}$ del mismo medio líquido bajo iguales condiciones de incubación. Cuando se obtuvo el crecimiento del micelio sobre la superficie, se recuperó y filtró a través de varias capas de gasa, agregándole

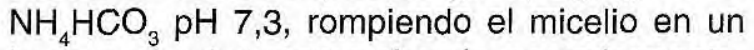
homogenizador y comprobando, posteriormente, mediante el uso de un microscopio de luz, un $80 \%$ de ruptura.

Se ultracentrifugó a $12.000 \mathrm{~g}$ por $30 \mathrm{~m}$ con el fin de remover por completo los restos miceliares (14). El sobrenadante se filtró al vacío a través de membranas de $0,45 \mu$ dializándose contra agua destilada toda la noche. Una vez dializado, el extracto se dividió en alícuotas, guardándose a $-20^{\circ} \mathrm{C}$ o se liofilizó. De esta forma, quedó listo el extracto para su estudio bioquímico e inmunológico.

\section{Evaluación del antígeno}

a. Bioquímica: la evaluación bioquímica del antígeno se llevó a cabo cuantificando la concentración total de carbohidratos y de proteínas.

Para la cuantificación de proteínas totales se utilizó el método de Bradford (33) con seroalbúmina bovina (BSA) como patrón y, en la cuantificación de carbohidratos totales, el método fenol-ácido sulfúrico de Dubois (34) con estándares de xilosa para las pentosas y de glucosa y galactosa para las hexosas.

b. Inmunológica: la evaluación inmunológica del antígeno, se realizó mediante el uso técnicas como la doble inmunodifusión en gel de agarosa (DD), contrainmunoelectroforesis con inmunodifusión secundaria y el enzimoinmunoensayo (ELISA), enfrentando el extracto antigénico contra sueros negativos, positivos y de referencia, y comparando las respuestas con las obtenidas con un antígeno de referencia. El suero y el antígeno de referencia fueron donados gentilmente por la doctora Angela Restrepo (CIB, Medellín).

Para conformar el grupo de control negativo, se seleccionaron 20 individuos aparentemente sanos a quienes previamente se les practicó una historia clínica cuidadosa incluyendo una radiografía de tórax, con el fin de descartar una posible aspergilosis. A cada uno de ellos se les tomó una muestra de sangre, extrayendo el suero y dividiéndolo en alícuotas y conservándolos a $-20^{\circ} \mathrm{C}$ para la realización posterior de las pruebas serológicas. Se siguió igual procedimiento en 7 pacientes con sospecha clínica y radiológica de aspergilosis pulmonar y que presentaron cultivo de esputo positivo para $A$. fumigatus.

El suero positivo de referencia se tituló antes de hacer las pruebas, enfrentándolo con el antígeno de referencia, por medio de la técnica de doble inmunodifusión en gel de agarosa, obteniéndose títulos hasta 1:16.

1. Doble inmunodifusión en gel de agarosa o análisis de Ouchterlony: se realizó enfrentando los dos antígenos contra los 20 sueros negativos y los sueros positivos, con el fin de evidenciar la presencia de bandas de precipitina. Para ello, se empleó agarosa al $1 \%$ (Standard Low Bio Rad) más polietilenglicol, con perforaciones según patrones ya establecidos e incubando las muestras durante un período de 72 horas, al final del cual se hizo una lectura inicial contra un fondo oscuro, para posteriormente secar y teñir los geles con azul de Coomasie R-250 $(35,36)$. Las bandas inespecíficas se eliminaron mediante el uso de citrato de sodio al $5 \%$.

2. Contrainmunoelectroforesis en gel de agarosa más inmunodifusión secundaria: utilizamos la técnica descrita por Amaral Olivera en la cual la contrainmunoelectroforesis tradicional se completa con una doble inmunodifusión secundaria que permite demostrar la existencia de componentes antigénicos de migración catódica (37). Para realizarla, se empleó agarosa al $1 \%$ disuelta en barbital tamponado, haciendo la corrida electroforética por 90 minutos en un equipo para electroforesis horizontal (Electrophoresis unit submarine Minigel 
Sigma). En la inmunodifusión secundaria seguimos los mismos pasos de lectura, secado y teñido de los geles empleados en la doble inmunodifusión. Esta técnica aunque más demorada, aumenta la especificidad de la prueba en un $95 \%$ (38).

3. Reacción de identidad: empleamos un esquema diseñado en nuestro laboratorio (figura 1) según el cual, al pozo central le agregamos el suero positivo de referencia (S) y a los cuatro pozos periféricos, los dos antígenos, tanto el de referencia ( $\mathrm{Ar}$ ) como el micelial (Mc), con el fin de visualizar reacciones de identidad por duplicado. Para la visualización de las bandas de identidad total, parcial o no identidad, seguimos los mismos pasos que para las dos pruebas anteriores.

4. Enzimoinmunoensayo (ELISA): para esta prueba se empleó una modalidad de ELISA no competitiva e indirecta, en la cual fijamos inicialmente el antígeno a una fase sólida (25, 39). Los antígenos se utilizaron en varias diluciones, con el fin de determinar la mejor dilución de trabajo, encontrando que la dilución 1:10 era la más adecuada.

El antígeno micelial se diluyó en carbonato de sodio tamponado, $\mathrm{pH} 9,6$, fijándolo en microplacas de poliestireno (Dinatech Laboratories) con fondo en U. Los pozos se llenaron con $100 \mu \mathrm{L}$ de la dilución, colocando las microplacas toda la noche a $4^{\circ} \mathrm{C}$ y lavándolas posteriormente con solución de ensayo (PBSTween 20) y bloqueando los sitios inespecíficos agregando $100 \mu \mathrm{L}$ de carbonato de sodio tamponado más BSA.

Realizamos nuevamente lavados con la solución de ensayo y agregamos los sueros negativos y los positivos (pacientes y de referencia) a cada uno de los pozos y por triplicado a una dilución de 1:100 (dilución previamente establecida como adecuada para la prueba), incubando por 2 horas, al cabo de las cuales y después de lavar las microplacas, agregamos IgG de conejo antihumana marcada con peroxidasa de rábano picante (Dako Laboratories) a una dilución 1:1.000, incubándolas en cámara húmeda. Revelamos la reacción enzimática agregando ortofenilendiamenia (OPD) más citrato fosfato y peróxido de hidrógeno como solución sustrato, incubando las placas a temperatura ambiente y protegidas de la luz. La reacción enzimática fue detenida, mediante la aplicación de 100 $\mu \mathrm{L}$ de ácido sulfúrico $0,5 \mathrm{M}$ a cada uno de los pozos y leyendo en un espectrofotómetro (Organon Teknika) a $492 \mathrm{~nm}$, siendo el tiempo de duración total de la prueba, aproximadamente de 5 horas.

\section{Resultados}

\section{Concentración de proteínas y carbohidratos}

En el presente estudio se evaluaron las características bioquímicas y antigénicas de un extracto micelial de $A$. fumigatus comparando los resultados obtenidos con un antígeno de referencia.

La determinación de proteínas totales mediante el método de Bradford hecho a los dos antígenos, no demostró diferencia significativa entre ellos ya que la concentración de proteínas del antígeno micelial fue de $8.800 \mu \mathrm{g} / \mathrm{mL}$ con respecto a la del antígeno de referencia de $8.200 \mu \mathrm{g} / \mathrm{mL}$.

En cuanto a la determinación de carbohidratos por el método fenol-ácido sulfúrico de Dubois, las lecturas para las hexosas mostró un valor total de $1.682,5 \mu \mathrm{g} / \mathrm{mL}$ en el antígeno Mc y $1.385 \mu \mathrm{g}$ en el antígeno $\mathrm{Ar}$, encontrándose una mayor concentración de galactosa en ambos antígenos con respecto a los otros carbohidratos. La concentración de pentosas fue de $770 \mu \mathrm{g} / \mathrm{mL}$ en el antígeno $\mathrm{Mc}$ y de $580 \mu \mathrm{g} / \mathrm{mL}$ en el antígeno Ar, con una concentración de carbohidratos totales en el antígeno $\mathrm{Mc}$ de $2.452,5 \mu \mathrm{g} / \mathrm{mL}$ y de 1.975 $\mu \mathrm{g} / \mathrm{mL}$ en el Ar.

\section{Evaluación del antígeno}

Doble inmunodifusión en gel de agarosa (DD): al enfrentar los dos antígenos contra los sueros positivos y negativos, los resultados fueron similares, no observándose bandas de precipitina con ninguno de los sueros negativos aún después de prolongar la incubación hasta los ocho días y seguir el proceso de eliminación de las bandas inespecíficas, secado y teñido final de las placas 
con azul de Coomassie. En dos de los cuatro sueros provenientes de pacientes con impresión clínica de aspergilosis, se presentaron bandas de precipitina al enfrentarse con los dos antígenos $\mathrm{Mc}$ y Ar. Con el suero de referencia, se observaron respuestas similares en los dos antígenos estudiados.

Reacción de identidad: los dos antígenos, Mc y $\mathrm{Ar}$, produjeron tres bandas de precipitina cada uno, visualizándose una de dichas bandas con identidad parcial y las dos restantes como identidad total (figura 1).

Contrainmunoelectroforesis más inmunodifusión secundaria ( $\mathrm{CIE}+\mathrm{DD})$ : ninguno de los 20 sueros negativos produjo bandas de precipitinas con los dos antígenos, a pesar de que se prolongó la inmundifusión por espacio de ocho días, como en la prueba anterior. Al emplear el suero positivo de referencia, se observaron bandas tanto en el lado catódico como en el anódico del pozo donde se ubicó el antígeno (figura 2). Con el antígeno Ar se visualizó una mejor banda en el lado anódico que con el antígeno micelial. De los sueros de pacientes, sólo dos sueros dieron respuestas positivas para los dos antígenos, con bandas muy tenues en el lado anódico.

Enzimoinmunoensayo (ELISA): con respecto a la técnica de ELISA y después de realizar varias pruebas iniciales con el fin de encontrar las diluciones ideales de trabajo para los antígenos,

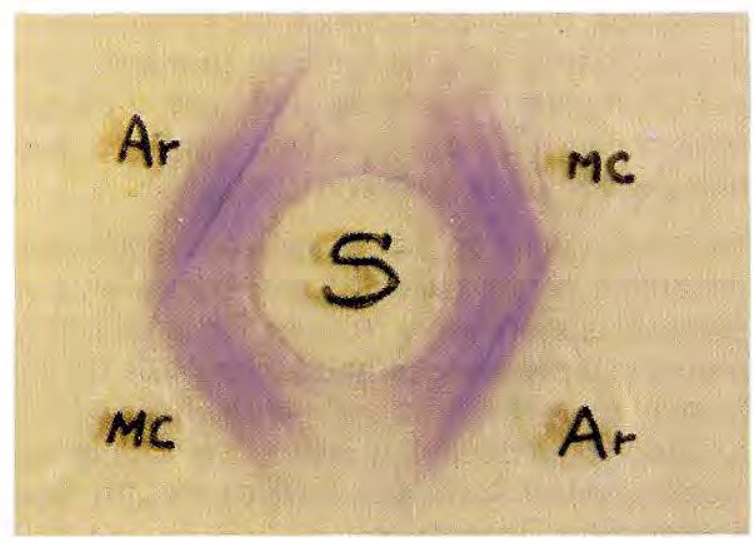

Figura 1. Bandas de reacción de identidad parcial y total entre el antígeno micelial (Mc) y el antígeno de referencia (Ar) de Aspergillus fumigatus.

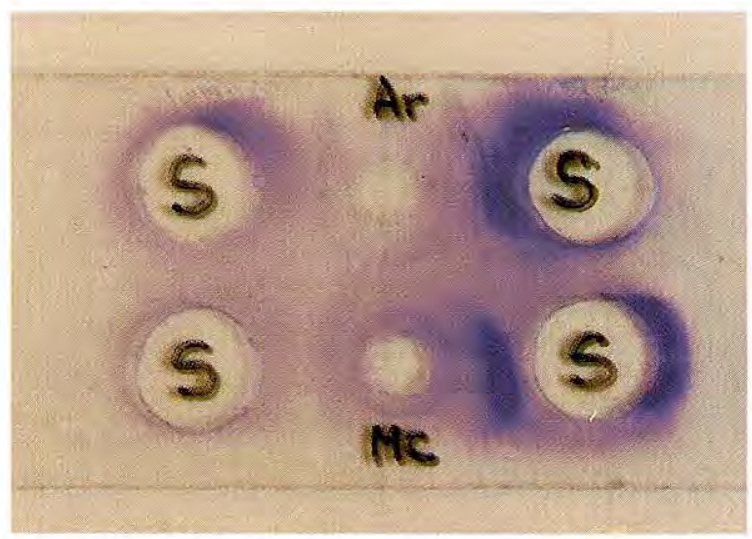

Figura 2. Contrainmunoelectroforesis más inmunodifusión secundaria del antígeno micelial (Mc) y antígeno de referencia (Ar) de Aspergillus fumigatus, en donde se visualizan las bandas de precipitina en los lados anódico y catódico de ambos antígenos.

los sueros, el conjugado IgG antihumana, los tiempos y temperaturas de incubación, número de lavados y concentración de los reactivos, se logró optimizar y estandarizar una técnica de ELISA indirecta no competitiva, en la que la dilución más adecuada fue de 1:10 (820 a 880 $\mu \mathrm{g}$ de proteínas $/ \mathrm{mL}$ ), la dilución de los sueros $1: 100$ y para la IgG antihumana $1: 1.000$, con una variación menor del $5 \%$ entre las densidades ópticas en cada una de las muestras evaluadas por triplicado.

Al realizar la c'istribución de las densidades ópticas obtenidas para los dos antígenos, observamos gráficamente que el punto de corte para considerar como seronegativo un suero correspondió a la media más dos desviaciones estándar o sea el valor de 0,352, lo que está de acuerdo con publicaciones anteriores en las cuales también se consideraron dos desviaciones estándar para establecer el punto de corte, lo que nos asegura un margen de confianza del $95 \%$ (figura 3$)(13,16)$.

De los siete sueros provenientes de los pacientes con sospecha clínica y radiológica de aspergilosis pulmonar, solamente los dos que fueron positivos para las pruebas de ID y CIE+DD secundaria presentaron densidades ópticas por encima del punto de corte, por lo que se pudo confirmar la impresión clínica inicial (figura 3). 


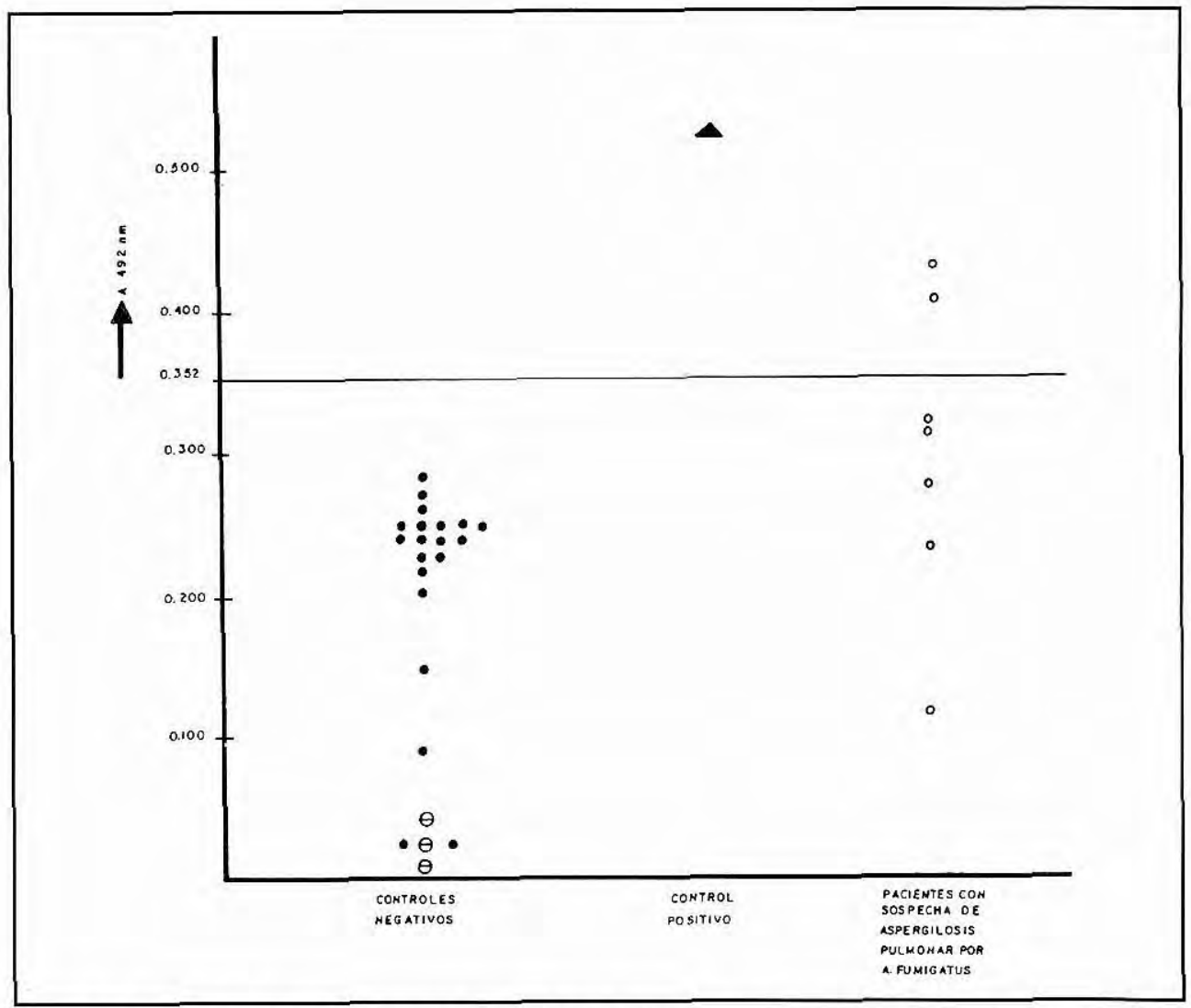

Figura 3. Resultados de las densidades ópticas en la determinación de lgG contra el antígeno micelial de Aspergillus fumigatus (Mc) en el grupo de sueros control negativo $(\bullet)$, sueros de pacientes $(0)$, suero de referencia $(\boldsymbol{\Delta})$ y blanco en ausencia de suero $(\theta)$ utilizando ELISA indirecta, con un punto de corte de 0,352 .

\section{Discusión}

Los antígenos de $A$. fumigatus que se emplean en pruebas serológicas y en otras técnicas inmunológicas son, en general, extractos crudos obtenidos ya sea a partir del medio de cultivo o del mismo organismo (16). Estos extractos, sin embargo, a pesar de contener sólo una pequeña parte de material realmente antigénico (una compleja mezcla de proteínas y carbohidratos), la cual puede variar en concentración aún entre diferentes lotes de una misma cepa $(16,20)$, han demostrado gran utilidad al ser empleados en pruebas para el diagnóstico de las aspergilosis, obteniéndose muy buenos resultados finales $(9,14)$.

Sin embargo, las preparaciones comerciales muchas veces son de inferior calidad debido a que son obtenidas a partir de cepas de $A$. fumigatus conservadas durante largo tiempo en micotecas, lo cual ocasiona cambios bioquímicos y estructurales en el hongo, que se manifiestan por un bajo contenido de proteínas y carbohidratos con la consiguiente baja reactividad con el suero de los pacientes $(20,23)$.

En la actualidad, un gran número de laboratorios dependen de los extractos preparados en sus propias instalaciones y realizan inmunodifusión para estandarizar sus antígenos (40). De tal forma, que mientras no estén disponibles antígenos puros optimizados, los antígenos crudos son la única opción posible para utilizarlos en pruebas diagnósticas.

La determinación de galactosa en los extractos antigénicos es de gran ayuda, ya que se sabe 
que este glúcido hace parte de los galactomananos (16), un grupo de polisacáridos ampliamente estudiados, con una estructura aún no bien definida, con características antigénicas propias y a los que se les ha atribuido ser los responsables en cierto grado, de la reactividad cruzada intra e interespecies de hongos. Además, es la fracción antigénica que con mayor frecuencia se ha aislado del suero de pacientes con aspergilosis y de conejos después de infección experimental $(21,22,41)$. En el presente estudio se demostró que en ambos antígenos la concentración de galactosa fue mayor $(38,6 \%)$ comparada con la de los otros dos carbohidratos $(31 \%$ de glucosa y $30,4 \%$ de xilosa).

Los dos antígenos presentaron una concentración mayor de proteínas que de carbohidratos, valores que están de acuerdo con estudios anteriores $(17,22)$, lo cual es de suma importancia, ya que es bien conocido que las actividades antigénicas de los extractos están contenidas en mayor proporción en la fracción proteica y una pequeña actividad está presente en el componente polisacárido (42).

De acuerdo con estudios previos, para poder utilizar un extracto antigénico de $A$. fumigatus como antígeno de referencia, se necesita que éste reaccione con un antisuero homólogo de referencia y produzca al menos tres bandas de precipitina, las cuales forman líneas de identidad con las bandas de precipitina producidas por un antígeno de $A$. fumigatus de referencia conocido (40). Si los antígenos producen tres bandas de identidad más otras bandas, se consideran aceptables (34). Los resultados obtenidos en el presente trabajo nos permiten concluir que nuestro antígeno cumplió con los requisitos exigidos para poder considerarlo un antígeno de referencia, ya que presentó un mínimo de tres bandas de precipitina cuando fue enfrentado con un suero de referencia (figura 1).

Las pruebas bioquímicas y la reacción de identidad mostraron que existe un cierto grado de variabilidad entre los extractos antigénicos; sin embargo, cuando realizamos las pruebas serológicas y enfrentamos los dos antígenos con un grupo de sueros negativos, sueros de pacientes con impresión clínica de aspergilosis pulmonar y un suero positivo de referencia, observamos resultados similares, lo que garantiza. que nuestro antígeno puede ser empleado en estas pruebas diagnósticas y confirma que las diferencias son más de tipo cuantitativo que cualitativo $(20,43)$.

Existe evidencia que no todos los componentes antigénicos precipitantes se unen a la superficie del poliestireno y visceversa (27). Sin embargo, en este estudio no observamos diferencias significativas entre los resultados obtenidos en la DD, CIE+DD y ELISA. Sería bueno emplear en futuros estudios, un número mayor de sueros de pacientes con alta sospecha de aspergilosis y de controles negativos con el fin de obtener resultados más concluyentes.

En Colombia, las técnicas de uso más corriente en el diagnóstico de las enfermedades producidas por este tipo de hongos son las de inmunoprecipitación (DD en gel de agar y CIE) $(8,9,40)$. La prueba de ELISA, de la cual no tenemos antecedentes de que se haya estandarizado en nuestro país para el estudio de las aspergilosis, tiene como característica principal el ser altamente sensible e identifica cantidades de anticuerpos en el orden de nanogramos (44). La $\mathrm{CIE}$ en sí es una prueba mucho más rápida que la DD y ha demostrado una gran sensibilidad y especificidad sobre todo cuando se asocia a la variante de DD secundaria, en la que la observación de un sólo sistema precipitante ya tiene significancia estadística de colonización aspergilar $(37,38)$; de ahí la importancia de incluirla en el presente estudio como un método complementario con la DD.

La detección de la actividad antigénica de un extracto puede depender en parte del sistema usado para evaluarlo, de la finalidad para la cual fue obtenido y del uso posterior que se le dará a dicho extracto. Utilizamos en el presente estudio, tres pruebas de sensibilidad y especificidad ampliamente demostradas en estudios previos $(9$, $15,37,45)$, ya que nuestro objetivo principal era utilizar este antígeno en pruebas de diagnóstico serológico (DD, CIE y ELISA), principalmente, aplicables a nuestros pacientes con alta sospecha de aspergilosis sin pensar en ningún momento que estas pruebas vayan a reemplazar técnicas 
más sencillas de realizar como las tinciones y el cultivo, sino que servirían de complemento para aumentar las posibilidades de un diagnóstico mucho más rápido y exacto.

La prueba de ELISA empleada, podría utilizarse para realizar un diagnóstico rápido y como evaluación del tratamiento, lo cual resultaría muy provechoso, ya que esta técnica es fácil de realizar en cualquier laboratorio empleándose sólo cinco horas, con el consiguiente beneficio para el paciente y para el médico, anulándose la espera que exige un cultivo positivo para instaurar el tratamiento adecuado.

Con este estudio se abre la posibilidad de utilizar el micelio del $A$. fumigatus en la extracción de antígenos para uso diagnóstico $(19,46)$. Además, la producción y caracterización de antígenos de tipo micelial y en un futuro próximo de los de tipo conidal y filtrado de cultivo a gran escala, beneficiaría a la comunidad, al cuerpo médico y a laboratorios clínicos en general. La técnica aquí empleada puede servir de base para la extracción de antígenos de otras especies pertenecientes al género Aspergillus, de reconocida importancia clínica. Se abre de este modo una línea de investigación que incluye, entre otros, el estudio de la epidemiología de la aspergilosis en nuestra región, la producción de antisueros y anticuerpos monoclonales dirigidos contra estos antígenos y la caracterización alergénica de los extractos, entre otros.

\section{Agradecimientos}

A los médicos, enfermeras, religiosas y, en especial, al doctor Gustavo Burgos, jefe de la sección de Neumología del Hospital San Pablo de Cartagena, por su amable cooperación.

Al grupo de docentes de la Facultad de Ciencias Químicas y Farmacéuticas, doctores Arnulfo Tarón, Humberto Herazo y María Teresa Vélez de López, por su colaboración en el desarrollo de algunas de las técnicas utilizadas en el estudio y en la revisión del manuscrito.

\section{Referencias}

1. López-Martínez R, Castañón LR, Rébora F y cols. Diagnóstico serológico de las micosis pulmonares por oportunistas. Rev Latinoam Microbiol 1988;30:3117.
2. Bodey GP, Vartivarian S. Aspergillosis. Eur J Clin Microbiol Infect Dis 1989;8:413.

3. Reyes E, Domínguez G, Acuña R. Infección or Aspergillus en el Instituto Nacional de la Nutrición Salvador Zubirán. Rev Invest Clin 1985;37:97.

4. Denning $D$, Stevens $D$. Antifungal and surgical treatment of invasive aspergillosis: review of 2,121 published cases. Rev Infect Dis 1990;12:1147.

5. Giraldo H, Castañeda E, Ordóñez N. Micosis profundas en el Amazonas colombiano. Hosmil Médica 1980;2:65.

6. Cook AM, Fortich A, Ramírez R. Aspergilosis broncopulmonar alérgica. latreia 1990;3:177.

7. Ramírez A, Ruiz O, Restrepo A, Robledo M, Sanjuán R. Aspergilosis pulmonar intracavitaria (aspergiloma). Antioquia Médica 1974;24:473.

8. Robledo J, Sierra F, Restrepo A y cols. Aspergiloma: su importancia como enfermedad pulmonar secundaria. Acta Med Colomb 1981;6:279.

9. Yarzabal LA, Da Luz S, Josef M y cols. Pruebas de inmunoprecipitación en el diagnóstico de las aspergilosis. Rev Inst Med Trop Sao Paulo 1973;15:1.

10. Vizcaya S, Vidal R, López San Martín JL y cols. Métodos diagnósticos y control evolutivo de 54 aspergilomas pulmonares. Rev Clin Esp 1988;183:393.

11. Melchers W J, Verweij $\mathbf{P}$, van den Hurk $\mathbf{P}$, et al. General primer-mediated PCR for detection of Aspergillus especies. J Clin Microbiol 1994;32:1710.

12. Gugnani H, Reijula K, Kurup V, Fink J. Detection of IgG and IgE antibodies to Aspergillus fumigatus in human sera by immunogold assay. Mycopathologia 1990;109:33.

13. Harvey $\mathrm{CH}$, Longbotton JL. Development of a sandwich ELISA to detect IgG and IgG subclass antibodies specific for a major antigen ( $\mathrm{Ag} \mathrm{7)}$ of Aspergillus fumigatus. Clin Allergy 1986;16:323.

14. Yu B, Niki Y, Armstrong D. Use of immunoblotting to detect Aspergillus fumigatus antigen in sera and urines of rats with experimental invasive aspergillosis. J Clin Microbiol 1990;28:1575.

15. Holmberg K, Berdischwsky M, Young LS. Serologic immunodiagnosis of invasive aspergillosis. $\mathrm{J}$ Infect Dis 1980;141:656.

16. Hearn V, Mackenzie D. Antigenic structure of Aspergillus species. In: Kurstak E. Immunology of fungal disease. New York, 1989:87.

17. Kaufman HF, van der Heide S, Beaumont F, et al. The allergenic and antigenic properties of spore extracts of Aspergillus fumigatus: a comparative study of spore extracts with mycelium and culture filtrate extracts. J Allergy Clin Immunol 1984;73:567.

18. Longbotton J. Allergic bronchopulmonary aspergillosis: reactivity of $\mathrm{lgE}$ and IgG antibodies with antigenic compo- 
nents of Aspergillus fumigatus (IgE/lgG antigen complexes). J Allergy Clin Immunol 1982;72:668.

19. Burnie JP. Developments in the serological diagnosis of opportunistic fungal infectios. J Antimicrob Chemother 1991;28:23.

20. Martínez J, Torres JM. Caracterización de exoantígenos de Aspergillus fumigatus. Estudio de factores que influyen en su calidad. Allergol Inmunopathol 1985;13:501.

21. Longbotton JL, Austwick PK. Antigens and allergens of Aspergillus fumigatus. I. Characterization by quantitative immunoelectrophoretic techiques. JAllergy Clin Immunol 1986;78:9.

22. Longbotton JL. Antigens and allergens of Aspergillus fumigatus. II. Their further identification and partial characterization of a major allergen ( $\mathrm{Ag} 3$ ). J Allergy Clin Immunol 1986;78:18.

23. Kurup VP, ResnickA, Scribner GH, et al. Enzime profile and immunochemical characterization of Aspergillus fumigatus antigen. J Allergy Clin Immunol 1986;78:1166.

24. Fratamico PM, Burckeley. Identification and characterization of an immunodominant 58 kilodalton antigen of Aspergillus fumigatus recognized by sera of patients with invasive aspergillosis. Infect Immun 1991;59:309.

25. Latgé JP, Mountauvakil M, Debeaupuis, et al. The 18kilodalton antigen secreted by Aspergillus fumigatus. Infect Immun 1991;59:2586.

26. Burnie JP, Matthews RC. Heat shock protein 88 and Aspergillus infection. J Clin Microbiol 1991;29:2099.

27. Kauffiman H F, Beaumont F, Meurs $\mathbf{H}$, et al. Comparison of antibody measurements against Aspergillus fumigatus by means of double-diffusion and enzime linked immunosorbent assay (ELISA). J Allergy Clin Immunol 1983;72:255.

28. Puente $P$, Ovejero MC, Fernández N, Leal F. Analysis of Aspergillus nidulans conidial antigens and their prevalence in other Aspergillus species. Infect Immun 1991;59:4478.

29. Qi-jin Tong, Wan-xing Chai, Zeng-fang Waqng, et al. A case of cerebral aspergillosis caused by Aspergillus nidulans: clinical, pathologic and mycologic identifications. Chin Med J 1990;103:518.

30. Kimura M, Udagawa Sh, Shoji A, et al. Pulmonary aspergillosis due to Aspegillus terreus combined with staphylococcal pneumonia and hepatic candidiasis. Mycopathologia 1990;111:47.

31. Rippon JW. Micología Médica. Tercera edición. México: Editorial Interamericana-McGraw Hill, 1990:668.
32. Haynes KA, Latge JP, Rogers TR. Detection of Aspergillus antigens associated with invasive infection. J Clin Microbiol 1990;28:2040.

33. Dunbar BS. Two dimensional electrophoresis and immunological techniques. New York: Plenum Press, 1987:143.

34. Palmer DF, Dauffman K, Kaplan W, Cavallaro JJ. Serodiagnosis of mycotic diseases. Springfield: Charles C. Thomas, 1977:11.

35. Outcherlony O, Nilsson LA. Immunodiffusion and immunoelectrophoresis. In: Weir DM, editor. Handbook of experimental immunology. Fourth ed. Oxford: Blackwell Scientific Publications, 1986:32.

36. Restrepo A. La prueba de inmunodifusión en el diagnóstico de la paracoccidioidomicosis. Sabourandia 1966;4:223.

37. Amaral O. Interés de las técnicas de inmunoprecipitación en el diagnóstico de las enfermedades producidas por hongos. I Congreso Nacional de Técnicos de Laboratorio. Barcelona, 1988:13.

38. Negroni R. Inmunología de las micosis. En: Margni, editor. Inmunología e inmunoquímica. Buenos Aires: Editorial Panamericana, 1989:427.

39. Nieto A, Carbonetto CH. Enzimoinmnoenzayo (ELISA). En: Margni, editor. Inmunología e inmunoquímica. Buenos Aires: Editorial Panamericana, 1989:571.

40. Restrepo A. La inmunodifusión en gel de agar y la inmunofluorescencia en el diagnóstico de las micosis pulmonares. Antioquia Médica 1972;22:337.

41. De Repentigny L, Boushira M, Ste-Marie L, Bosisio G. Detection of galactomannan antigenemia by enzime immunoassay in experimental invasive aspergillosis. J Clin Microbiol 1987;25:863.

42. Vernes A. Humoral response in aspergillosis. In: Kurstak E. Immunology of fungal disease. New York, 1989:401.

43. Lirio V de S, Assis CM, Cano MI, Lacaz C da S. Obtenção e avaliação de antígenos de Aspergillus fumigatus. Rev Inst Med Trop Sao Paulo 1992;34:359.

44. Greenbenger P, Patterson R. Aplication of enzyme-linked immunosorbent assay (ELISA) in diagnosis of allergic bronchopulmonary aspergillosis. J Lab Clin Med 1982;99:288.

45. Faux JA, Shale DJ, Lane DJ. Precipitins and specific IgG antibody to Aspergillus fumigatus in a chest population. Thorax 1992;47:48.

46. Girardin H, Sarfati J, Traoré F, et al. Molecular epidemiology of nosocomial invasive aspergillosis. J Clin Microbiol 1994;32:684. 